\title{
Balıklardan izole edilen bakteriyel etkenler: Beş yıllık değerlendirme
}

\author{
Zeynep Şık1 (), Özlem Altıntaş (), Enes Gazi Atıcı ${ }^{3}$ (1) \\ 1,2,3 Veteriner Kontrol Merkez Araştırma Enstitüsü Müdürlüğü, Su Ürünleri Hastalıkları Teşhis ve Araştırma Lab., Ankara, Türkiye
}

Geliş Tarihi / Received: 23.03.2020 Kabul Tarihi / Accepted: 18.05.2020

\begin{abstract}
Özet: Bu çalışmada, 2015-2019 yılları arasında Veteriner Kontrol Merkez Araştırma Enstitüsü Su Ürünleri Hastalıkları Araştırma ve Teşhis Laboratuvarı'na gönderilen balık örneklerinden izole edilen bakteriyel etkenlerin dağılımı ve bu etkenlerin de bölgesel ve aylara göre dağılımı incelenmiştir. Bu süreçte laboratuvara gönderilen balık örneklerinden etken izolasyonu ve identifikasyonu, aseptik şartlarda konvansiyonel yöntemler ve hızlı teşhis kitleri (Vitek 2) kullanılarak gerçekleştirilmiştir. Çalışmada 60 adet balık örneği incelenmiş ve bunların 27'sinde bakteriyel etken izole edilmiştir. İzole edilen etkenlerin dağılımının; Aeromonas sobria (\%23,3), Aeromonas hydrophila (\%6,7), Shewanella putrefaciens (\%5), Aeromonas veroni (\%3,3), Serratia rubidaea $(\% 1,7)$, Kocuria rhizophila $(\% 1,7)$, Streptococcus iniae $(\% 1,7)$, Pseudomonas aeruginosa $(\% 1,7)$ ve Proteus spp. $(\% 1,7)$ oranında olduğu belirlendi. Elde edilen sonuçlar göre; 2015-2019 yılları arasında balıklardan en fazla izole edilen etkenin A. sobria olduğu görülmüştür. Yine balıklardan izole edilen bakteriyel etkenlerin bölgesel ve aylara göre dağılımı incelendiğinde; bu etkenlerin en yaygın Haziran, Ağustos, Eylül, Ekim aylarında ve Ankara, Bolu, Kastamonu illerinde görüldüğü belirlenmiştir.
\end{abstract}

Anahtar kelimeler: Bakteriyel Enfeksiyonlar, Balık, Vitek 2

\section{Bacterial agents isolated from fish: A five year evaluation}

\begin{abstract}
In this study, the distribution of bacterial factors isolated from the fish samples sent to the Veterinary Control Central Research Institute Fisheries Diseases Research and Diagnosis Laboratory between 2015-2019 and the distribution of these factors by regional and months were examined. In this process, the isolation and identification of the causative agent from fish samples sent to the laboratory was carried out using conventional methods and rapid diagnostic kits (Vitek 2). In the study, 60 fish samples were examined and bacterial agents were isolated in 27 of them. The distribution of the isolated bacteria; Aeromonas sobria $(\% 23,3)$, Aeromonas hydrophila $(\% 6,7)$, Shewanella putrefaciens (\%5), Aeromonas veroni $(\% 3,3)$, Serratia rubidaea $(\% 1,7)$, Kocuria rhizophila $(\% 1,7)$, Streptococcus iniae $(\% 1,7)$, Pseudomonas aeruginosa $(\% 1,7)$ and Proteus spp. $(\% 1,7)$ was determined. According to the results obtained; $A$. sobria was observed to be the most isolated factor from fish between 2015-2019. When the distribution of bacterial species isolated from fish by regions and months is examined; It is determined that these bacteria are most common in June, August, September, October and in Ankara, Bolu, Kastamonu provinces.
\end{abstract}

Key words: Bacterial infections, Fish, Vitek 2

\section{Giriş}

Su ürünleri yetiştiriciliği yoluyla gıda üretimi dünya genelinde oldukça hızlı bir gelişme göstermiştir. Bu gelişmelere paralel olarak kültür balıkçılığında çok sayıda balığın bir arada ve yakın temas halinde bulunması, doğada (dere, göl, gölet, deniz, vs) serbest yaşayanlara oranla, daha fazla hastalığın ortaya çıkmasına neden olmaktadır. Balıkların içinde yaşadıkları ortamın (tuzlu, acı, tatlı su) sınırlı olan besleyici, fiziksel, kimyasal, biyotik ve abiyotik optimal yaşam koşullarının olumsuz yönde değişmesi bunların kısa süre içinde düzelmemesi ve devam etmesi (Arda ve ark. 2005) sektörde ciddi kayıplarla sonuçlanan; viral, paraziter, fungal ve özellikle birçok bakteriyel hastalığın ortaya çıkmasına neden olmaktadır. Su ürünleri yetiştiriciliğinde balıklarda hastalık etkenlerinin teşhisi ve dağılımıyla ilgili çalışmalar, hastalık kontrol stratejilerinin geliştirilmesine katkı sağlayacaktır. Çünkü bazı patojen mikroorganizmalar halk sağlığı açısından önemlidir (Wanja ve ark. 2019).

Dünyada olduğu gibi Türkiye'de de üretimi yapılan isletmelerde oldukça sık rastlanan başlıca patojen bakteriyel etkenler arasında en çok izole edilen Aeromonas genusuna ait türlerdir. Aeromonas genusu, Aeromonadaceae familyası altında yer alan Gram negatif, fakültatif anaerob, sitokrom oksidaz ve katalaz pozitif, nitratı nitrite dönüştürürler, $\mathrm{O} / \mathrm{F}$ glukoz testinde fermantatif reaksiyon veren ve Vibriostat $(\mathrm{O} / 129)$ testine dirençli, sporsuz çomak şeklinde bakterilerdir. Doğal yaşam alanları deniz ve tatlı sulardır. Sularda yaygın varlığı nedeniyle, etkenler tatlı su ve deniz balıklarının, kabuklu hayvanların ve amfibianların bağırsak florasında ve vücut yüzeylerinde bulunurlar. Bazı türleri insan, balık ve diğer akuatik 
hayvanlarda enfeksiyonlara neden olur (Akaylı ve ark. 2011; John 2014; Fernandez-Bravo ve Figueras 2020). Önemli balık patojenleri olan $A$. hydrophila, $A$. sobria, A.caviae gibi hareketli Aeromonas türleri hemorajik septisemi (Hareketli Aeromonas Septisemisi, MAS) ile seyreden enfeksiyonlara neden olur. Enfeksiyonun inkübasyon süresi 2-4 gündür. Enfekte balıkların baş, yüzgeç, karın bölgelerinde hemorojik alanlar görülür. İç organlarda septisemiye bağlı hemorojik bir tablo dikkat çeker. Mortalite yüksektir. Hareketsiz Aeromonas türü olan A. salmonicida ise çeşitli balık türlerinde furunkulosis enfeksiyonuna neden olur. Akut olaylarda lezyon görülmeden ölüm şekillenir. Kronik enfeksiyonlarda yüzgeç ve kuyruk diplerinde furunkuller oluşur. İç organlarda septisemi görülür (Toranzo ve ark. 1989; Esteve ve ark. 1993; Wahli ve ark. 2005; Aydın ve Paracıkoğlu 2006; Austin ve Austin 2007; Wanja ve ark. 2019). Bu bakteriyel etkenler yüksek mortalite ile seyreden enfeksiyonlarda primer etken olarak sorumlu olsa da konağın normal florasında bulunan bazı mikroorganizmalar konağın immun sistemi baskılandığında sekonder enfeksiyon olarak ortaya çıkabilir (John 2014). Bu enfeksiyonlar su ürünleri yetiştiriciliğinde büyük ekonomik kayıplara neden olmaktadır.

2015-2019 yılları arasında Veteriner Kontrol Merkez Araştırma Enstitüsü (VKMAE) Su Ürünleri Hastalıkları Araştırma ve Teşhis Laboratuvarı'na, Ankara, Kayseri, Bolu, Çankırı, Çorum, Bartın, Kastamonu, Karabük, Yozgat, Nevşehir, Kırıkkale, Ordu, Eskişehir, Sivas, Zonguldak illerinden gönderilen örnekler incelenmiştir. Bu çalışmanın amacı, 2015-2019 yıllarında bakteriyel etkenlerin araştırılması amacıyla gönderilen balık örneklerinden elde edilen sonuçları retrospektif olarak değerlendirmektir.

\section{Gereç ve Yöntem}

Bu çalışmaya 2015-2019 tarihleri arasında VKMAE Su Ürünleri Hastalıkları Teşhis ve Araştırma Laboratuvarı'na hastalık teşhisi amacıyla gönderilen yabani, çiftlik ve akvaryum balık örneklerinden izole edilen bakteriler dahil edilmiştir. Araştırmada 60 adet balık örneği kullanılmıştır. Balık örneklerinin abdominal bölgesinin derisi \%70'lik etil alkol ile temizlendikten sonra dorsoventral olarak diseksiyonu yapıldı ve balıkların iç organlarından (karaciğer, dalak, beyin ve böbrek) \%5 koyun kanlı agar (Oxoid, İngiltere), MacConkey agar (Oxoid, İngiltere), Nutrient agar (Oxoid, İngiltere) besiyerine bakteriyolojik ekimler yapılmıştır. Yapılan bakteriyolojik ekimler 24-48 saat $21^{\circ} \mathrm{C}$ 'de inkübe edilmiş ve inkübasyon sonunda üremeler değerlendirilmiştir. Bu amaçla; Gram boyama yapılarak mikroskobik morfolojileri incelenmiştir. Bakteriyel izolatların tanımlanmasında biyokimyasal testleri Vitek 2 (bioMérieux, Fransa) hızlı tanı kitleri üretici firmanın talimatları doğrultusunda kullanılmıştır.

\section{Bulgular}

Çalışmada 60 balık örneği incelenmiş ve 27'sinde bakteriyel etken izole edilirken, 33 örnekte izolasyon gerçekleşmemiştir. Bakteriyel etkenlerin balık türlerine göre dağılımı ise; 13 alabalıktan (5 A. sobria, 2 A. hydrophila, A. veroni, S. rubidaea, Proteus spp., 2 S. putrefaciens, $P$. auregenisa), 1 gümüş balığından (A. sobria), 1 mersin balığından (A. sobria), 1 pullu sazandan ( $A$. sobria), 10 sazandan (6 A. sobria, $A$. hydrophila, A. veroni, S. putrefaciens, K. rhizophila), 1 zebra balığından (A. hydrophila ve S. iniae) izole edilmiştir. Bakterilerin çoğunluğu Gram negatif $(\% 92,9)$ iken Gram pozitif bakterilerin oranı daha düşüktür $(\% 7,1)$. Örneklerden en sık izole edilen etkenler $A$. sobria $(\% 23,3)$, A. hydrophila $(\% 6,7)$, S. putrefaciens (\%5), A. veroni $(\% 3,3)$ 'dir. Diğer bakteriyel etkenler S. rubidaea $(1,7), K$. Rhizophila $(1,7)$, S. iniae $(1,7), P$. aureginosa $(1,7)$ ve Proteus spp. $(1,7)$ izole edilmiştir (Tablo 1). Çalışmamızda en sık pozitif olgu sayısı Haziran, Ağustos, Eylül ve Ekim gibi su sıcaklığının yüksek olduğu aylarda saptanmıştır (Tablo 3). İllere göre pozitif olgu sayısının yoğunluğu ise Ankara, Bolu ve Kastamonu'da gözlenmiştir (Tablo 4).

Tablo 1: Balıklardan izole edilen bakteriyel etkenlerin dağılımı

\begin{tabular}{lcccc}
\hline Bakteriler & Toplam sayı & Bakteri saptanan örnekler içindeki oran & Tüm örnekler içindeki oran \\
\hline Aeromonas hydrophila & 4 & 14,3 & 6,7 \\
Aeromonas veronii & 2 & 7,0 & 3,3 \\
Aeromonas sobria & 14 & 50,0 & 23,3 \\
Serratia rubidaea & 1 & 3,6 & 1,7 & 5,0 \\
Shewanella putrefaciens & 3 & 10,7 & 1,7 \\
Proteus spp. & 1 & 3,6 & 1,7 \\
Pseudomonas aeruginosa & 1 & 3,6 & 1,7 \\
Kocuria rhizophila & 1 & 3,6 & 1,7 \\
Streptococcus iniae & 1 & 3,6 & \\
\hline
\end{tabular}


Tablo 2: Örneklerin mevsimlere göre dağılımı (2015-2019)

\begin{tabular}{lccc}
\hline Mevsim & Örnek sayısı & Pozitif Olgu & Negatif Olgu \\
\hline Kış & 5 & 4 & 1 \\
İlkbahar & 8 & 3 & 5 \\
Yaz & 31 & 9 & 22 \\
Sonbahar & 16 & 11 & 5 \\
Toplam & 60 & 27 & 33 \\
\hline
\end{tabular}

Tablo:3 Balıklardan izole edilen bakteriyel etkenlerin aylara göre dağılımı (2015-2019)

\begin{tabular}{|c|c|c|c|c|c|c|c|c|c|}
\hline \multirow{2}{*}{ Aylar } & \multicolumn{9}{|c|}{ Etkenler } \\
\hline & A. hydrophila & A.veronii & A. sobria & S. rubidaea & Proteus spp. & S. putrefaciens & K. rhizophila & S. iniae & P. aeruginosa \\
\hline Ocak & 1 & - & 1 & - & - & 1 & - & - & - \\
\hline Şubat & - & - & - & - & - & - & - & - & - \\
\hline Mart & - & - & - & - & - & - & - & - & - \\
\hline Nisan & - & - & - & - & - & - & - & - & - \\
\hline Mayıs & 1 & - & 1 & - & - & - & - & - & 1 \\
\hline Haziran & - & 1 & 2 & - & - & 1 & - & - & - \\
\hline Temmuz & - & - & 1 & - & - & - & - & - & - \\
\hline Ağustos & - & 1 & 2 & - & 1 & - & - & - & - \\
\hline Eylül & - & - & 4 & 1 & - & - & 1 & - & - \\
\hline Ekim & 1 & - & 2 & - & - & - & - & 1 & - \\
\hline Kasım & - & - & 1 & - & - & 1 & - & - & - \\
\hline Aralık & 1 & - & - & - & - & - & - & - & - \\
\hline
\end{tabular}

Tablo 4: İllere göre pozitif olgulardan izole edilen bakterilerin dağılımı (2015-2019)

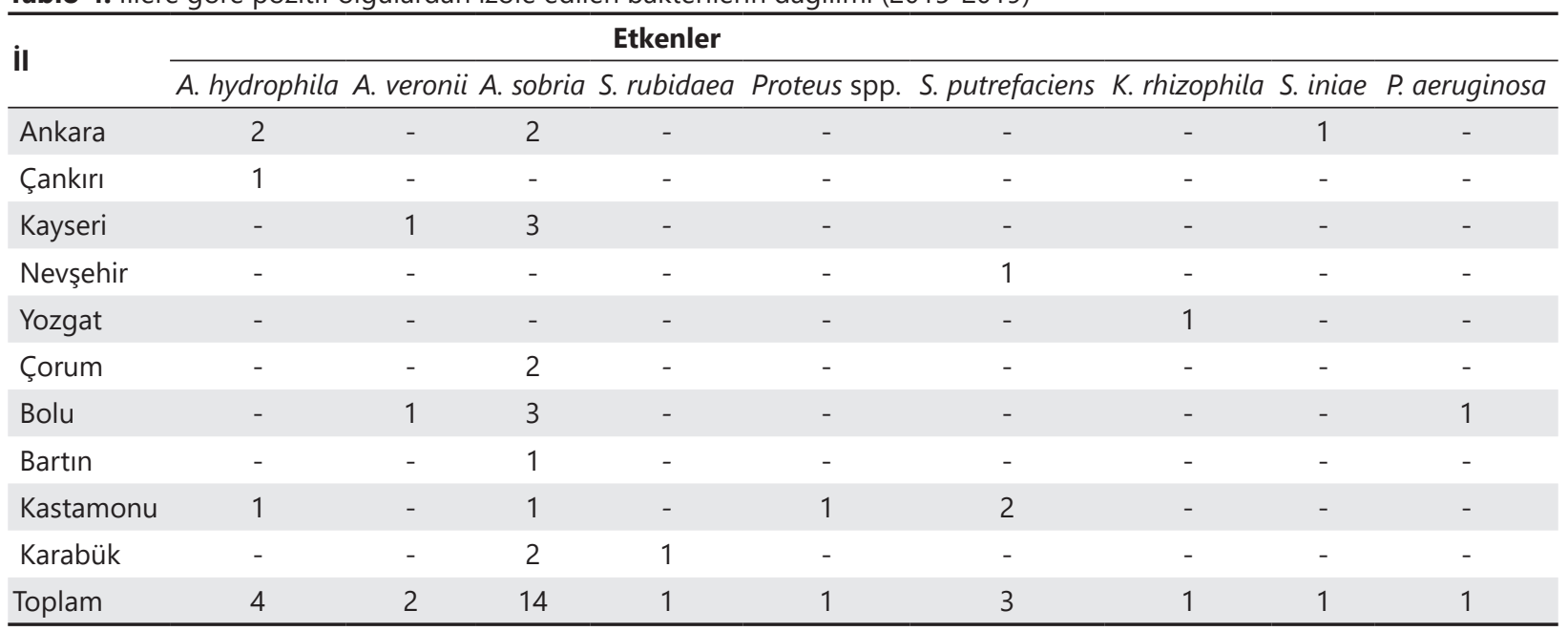

\section{Sonuç ve Tartışma}

Su ürünleri yetiştiriciliğini etkileyen önemli hastalıklar bakteri, mantar, virüs ve paraziter etkenlerden kaynaklanmaktadır. Birçok patojen arasında, bakteriler en önemli etiyolojik ajan grubunu oluşturur. Türkiye'de 48 patojenik bakteri raporlanmıştır. Rapor edilen hastalıklar arasında en yaygın görülen balık hastalıkları etkenleri Vibrio spp, Aeromonas spp,
Yersinia spp, Photobacterium spp ve Flavobacterium spp olduğu bildirilmiştir (Öztürk ve Altınok 2014). Bu çalışmada hasta balık örneklerinden $A$. sobria $(\% 23,3)$, A. hydrophila $(\% 6,7)$, S. putrefaciens $(\% 5), A$. veroni $(\% 3,3)$ ve diğer bakteriyel etkenler S. rubidaea, K. rhizophila, S. iniae, P. aureginosa ve Proteus spp. izole edilmiş̧ir. Bazı araştırmacıların (Erdem ve ark. 2010; Özkök 2005) aksine bu çalışmada örneklerden 
en sık izole edilen etken $A$. sobria $(\% 23,3)$ olmuştur. Bu sonuç $A$. sobria'nın hasta balıklarda yaygın olarak görüldüğünü bildiren araştırmacıları desteklemektedir (John 2014; Onuk ve ark. 2015). A. sobria'nın hasta balıklarda yüksek oranda izole edilmesi, sulardaki yaygın varlığı (Onuk ve ark. 2013; John 2014) nedeniyle etken tatı su ve deniz balıklarının bağırsak florasında ve vücut yüzeylerinde bulunmasıyla ilişkilendirilebilir. Normalde hastalık oluşturmayan etken konağın immun sisteminin zayıflaması veya çevre şartlarının değişmesine bağlı olara hastalık oluşturmuş olabilir.

Bakteriyel enfeksiyonlarının teşhisinde, bakterinin cins ve tür düzeyinde tanımlanabilmesi için klasik mikrobiyolojik tanı yöntemleri ile 16S rDNA dizi analizine dayanan moleküller yöntemler altın standart olarak kabul edilmekte ve önemini korumaktadır (Laupland ve Valiquette 2013). Klasik mikrobiyolojik tanı yöntemleri güvenilirdir ancak hızlı ve pratik olmayabilir. DNA dizi analiz yöntemleri bütün mikroorganizmaların tanımlanmasında altın standart olduğu tartışmasız olmakla birlikte, bu yöntemin rutin mikrobiyoloji laboratuvarlarında günlük kullanımı olası değildir (Erdem ve ark. 2017). Üstelik bazı teknik kısıtlamaları ve yüksek maliyeti de bulunmaktadır. Mikrobiyoloji laboratuarından, rutin örneklerin en hızlı şekilde işlenmesi ve en doğru sonucun iletilmesi beklenmektedir. Bu sebepler günümüzde hastalık etkenlerinin cins ve tür düzeyinde tanımlanabilmesi için araştırmacıları API ve VITEK (Carriero ve ark. 2016; Laith ve ark. 2017; Rosso ve ark. 2019) gibi hızlı teşhis kitlerinin kullanımına yöneltmiştir. Hızlı teşhis kitleri Aeromonas türlerinin fenotipik yakınlığı nedeniyle tür düzeyinde identifikasyonunda çok güvenilir sonuç vermese de benzer özellik gösteren türlerin tanımlanmasına olanak sağlamaktadır (Beaz-Hidalgo ve ark. 2010; Duman 2017; Fernandez-Bravo ve Figueras 2020). Bu çalışmada balık örneklerinden etken izolasyonu ve identifikasyonu, konvansiyonel yöntemler ve hızlı teşhis kitleri (Vitek 2) kullanılarak gerçekleştirilmiştir. 60 hasta balık örneğinin 27'sinde bakteriyel etken izole edilirken 33'inde izolasyon gerçekleşmemiştir. Negatif olgu sayılarının dağılımı sırasıyla en fazla yaz $(\% 36,7)$, ilkbahar $(\% 8,3)$ ve sonbahar $(\% 8,3)$ aylarında (Tablo 2) olduğu tespit edilmiştir, bu önemli bir bulgudur. Çünkü bazı araştırmacılar (Crear ve ark. 2020; Feidantsis ve ark. 2020) su sıcaklık değişiminin balıklarda metabolik hastalıklar oluşturması sonucunda ölümlere neden olduğunu bildirmiştir. Balık hastalıklarının teşhisinde sıcaklık değişiminin balıklar üzerindeki potansiyel etkilerinin değerlendirilmesi amacıyla balıkların fizyolojik ve çevresel to- leranslarının ölçülmesi çalışmalarına da gereksinim vardır. Çünkü çevre ısısı primer bir hastalık nedeni de olabilir. Biz sadece balıklarda hastalık oluşturan bakteriyel etkenler üzerine genel bir değerlendirme sunmaya çalıştık. Kültürlerden negatif sonuçların elde edilmesi hasta balıklara önceden antibakteriyel bir ilaç tedavisi uygulanmış olabileceğiyle ilişkilendirilebilir.

Çalışmamızda 2015-2019 yıları arasında farklı su sıcaklıkları ve akarsu tiplerinden (baraj, dere, göl, gölet, deniz, vs) gönderilen hasta balıklarda gözlenen en sık pozitif olgu sayısı Haziran (4), Ağustos (4), Eylül (6) ve Ekim (4) aylarında görülmüştür. Bu aylarda en yüksek oranda $A$. sobria, $A$. hydrophila ve $A$. veroni türleri tespit edilmiştir. Aeromonas türlerine kış aylarında da rastlanmıştır. S. putrefaciens hem kış aylarında hem de yaz aylarında izole edilmiştir. Deniz ve tatlı sularda yaygın olarak bulunan $S$. putrefaciens; balıklarda çoğunlukla deri ve yumuşak doku enfeksiyonları ile birlikte ülserlere ve nekrotik lezyonlara neden olur. Salgınlar esas olarak ilkbahar mevsiminde su sıcaklığının 7 ile $10^{\circ} \mathrm{C}$ olduğu zamanlarda, Aeromonas spp. ve Pseudomonas spp. enfeksiyonlarıyla birlikte seyreder. Shewanella türleri, hasta ve sağlıklı balıklardan ve sulardan izole edilebilirler (Jung-Schroers ve ark. 2017). Çalışmamızda sporadik olarak rastlanan; S. rubidaea, K. rhizophila, $P$. aureginosa, Proteus spp. türleri yaz aylarında izole edilmiştir. Sıcak su ( $15^{\circ} \mathrm{C}$ üzeri) Streptokokkosis'i olarak bilinen S. iniae, Ekim ayının başında A. hydrophila ile birlikte izole edilmiştir. Sonuç olarak su sıcaklığının yüksek olduğu aylarda yaygın olarak hareketli Aeromonas türleri izole edilmiştir. Çalışmamızda hasta balıklardan izole edilen bakteriyel etkenlerin dağılımında, örnekleme zamanı ile yaygın türler arasında yakın bir ilişki olduğu gözlenmiştir. Bazı araştırmacılar (Cavari ve ark. 1981; Lee ve ark. 2002) su sıcaklığının yüksek olduğu aylarda patojen Aeromonas türlerinin yaygın olarak bulunduğunu bildirmişlerdir. Bu bulgular doğrultusunda su sıcaklığının enfeksiyonun oluşmasında önemli bir yeri olduğu söylenebilir.

Duman'ın (2017) yaptığı tez çalışmasında 103 adet hareketli Aeromonas türünün kökenlerinin bölgesel olarak dağılımı rapor etmiştir. Bu rapor sonucunda hareketli Aeromonas türleri en sık İç Anadolu bölgesinde gözlendiğini bildirmiştir (Duman 2017). Bu çalışmada elde edilen sonuçlara göre hasta baIıklardan izole edilen etkenlerin illere göre dağılımı yapılmış ve iç Anadolu bölgesinde yer alan illerden yukarıda bildirilen araştırmacıyla benzer sonuçlar elde edilirken Batı Karadeniz bölgesinde yer alan illerde de en yüksek $A$. sobria izole edilmiştir. En fazla 
pozitif olgu sayısı Batı Karadeniz bölgesinde $(\% 51,8)$ gözlenmiştir. İllere göre en yüksek pozitif olgu sayısı Ankara, Bolu ve Kastamonu da tespit edilmiştir. P. aureginosa insan patojenidir. İnsana özgü olan bu patojenin bu araştırmada balıktan izole edilmesinin tespiti çok değerli bir bilgidir.

Çalışmamızda tespit edilen farklılıkların sebebi; konağa bağlı faktörler, patojen mikroorganizmaların doğal yaşam alanının deniz ve tatı sular olması, su kirliliği, stres, yetersiz beslenme, mevsime bağlı olarak değişen su sıcaklığı, coğrafi farklılıklar etkili olabilir. Aeromonas türlerinin su ve balıklarda yaygın olarak bulunması, mevsimsel ve bölgesel değişiklik göstermesi bilgilerine dayanarak bu bakterilerin neden olduğu enfeksiyonlar iyi değerlendirilmelidir. Sonuç olarak çalışmamızın bulguları, yurtdışı ve yurt içi çalışmaların birçoğu ile uyumlu olmakla birlikte sonuçların bölgesel olarak da değişebileceğini söyleyebiliriz.

Teşekkür: Bu çalışmanın her aşamasında emeği olan ve makalenin hazırlanmasında desteğini esirgemeyen laboratuvar şefimiz sayın Uzm. Veteriner Hekim Selahattin ŞEN'e teşekkür ederiz.

\section{Kaynaklar}

1- Akaylı T, Çanak Ö, Başaran B. (2011) Gökkuşağı alabalıklarında (Oncorhynchus mykiss Walbaum, 1792) görülen Aeromonas schubertii enfeksiyonu üzerine bir çalışma. Biyoloji Bilimleri Araştırma Dergisi 4, 99-106.

2- Arda M, Seçer S, Sarıeyyüpoğlu M. (2005) Balık Hastalıkları. Medisan Yayınları. Ankara.

3- Austin B, Austin DA. (2007) Bacterial Fish Pathogens. 4. Edt., UK, Praxis Publishing.

4- Aydın N, Paracıkoğlu J. (2006). Veteriner Mikrobiyoloji. İlke-Emek Yayınları.

5- Beaz-Hidalgo R, Alperi A, Bujan N, Romalde JL, Figueras MJ. (2010) Comparison of phenotypical and genetic identification of Aeromonas strains isolated from diseased fish. Syst. Appl. Microbiol. 33, 149-153.

6- Carriero AA, Mendes Maia AA, Moro Sousa RL, Henrique-Silva F. (2016) Characterization of a new strain of Aeromonas dhakensis isolated from diseased pacu fish (Piaractus mesopotamicus) in Brazil. J Fish Dis. 39, 1285-1295.

7- Cavari BZ, Allen DA, Colwell RR. (1981) Effect of temperature on growth and activity of Aeromonas spp. and mixed bacterial populations in the Anacostia River. Applied and Environmental Microbiology. 41,1052-1054.

8- Crear DP, Brill RW, Averilla LML, Meakem SC, Weng KC. (2020) In the face of climate change and exhaustive exercise: the physiological response of an important recreational fish species. $R$ Soc Open Sci 25;7(3):200049.

9-Duman M. (2017). Gökkuşağı alabalıklarında görülen motil Aeromonas (Aeromonas hydrophila, A. sobria, A. caviae), Yersinia ruckeri ve Lactococcus garvieae bakterilerinin antimikrobiyal duyarlılıkları ve duyarlılıkta rol oynayan genlerin tespiti. Doktora Tezi. Uludağ Üniversitesi Sağlık Bilimleri Enstitüsü, Bursa.

10- Erdem B, Kariptaş E, Kaya T. (2010) Siderophore, hemolytic, protease, and pyrazinamidase activities and antibiotic resistance in motil Aeromonas isolated from fish. Turk J Biol. 34, 453-462.
11- Erdem H, Erganiş S, Evren E, Aksakal FN, Çağlar K, Kalkancı A. (2017) Candida cinsi mayaların tür düzeyinde tanımlanmasında kullanılan yöntemlerin karşılaştırmalı analizi. Türk Mikrobiyol Cem Derg. 47, 114-124.

12- Esteve C, Biosca EG, Amaro C. (1993) Virulens of Aeromonas hydrophila ans some other bacteria isolatedfrom European eels, Anguilla Anguilla reared in fresh water. Dis. Aqua. Org. $16,15-20$.

13- Feidantsis K, Georgoulis I, Zachariou A, Campaz B, Christoforou M, Pörtner HO, Michaelidis B. (2020) Energetic, antioxidant, inflammatory and cell death responses in the red muscle of thermally stressed Sparus aurata. J Comp Physiol B. doi: 10.1007/ s00360-020-01278-1.

14- Fernandez-Bravo A, Figueras MJ. (2020) An Update on the Genus Aeromonas: Taxonomy, Epidemiology, and Pathogenicity. Microorganisms. 8, 129.

15- John N. (2014) Distribution, extracellular virulence factors and antibiogram of motile aeromonads in fresh water ornamental fishes and immune response of Cyprinus carpio against Aeromonas hydrophila infection. Thesis. Cochin University of Science and Technology.

16- Jung-Schroers V, Jung A, Ryll M, Bauer J, Teitge F, Steinhagen D. (2017) Methods for indentification and differentiation of different Shewanella spp. isolates for diagnostic use. J Fish Dis. 41, 689-714.

17- Laith AA, Ambak MA, Hassan M, Sheriff SM, Nadirah M, Draman AS, Wahab W, Ibrahim WN, Aznan AS, Jabar A, Najiah M. (2017) Molecular identification and histopathological study of natural Streptococcus agalactiae infection in hybrid tilapia (Oreochromis niloticus). Vet World. 10, 101-111.

18- Laupland KB, Valiquette L. (2013) The changing culture of the microbiology laboratory. J Infect Dis Med Microbiol. 24, 125-8.

19- Lee C, Cho J-C, Lee S-H, Lee D-G, Kim S-J. (2002) Distribution of Aeromonas spp. as identified by $16 \mathrm{~S}$ rDNA restriction fragment length polymorphism analysis in a trout farm. Journal of Applied Microbiology. 93, 976-985.

20- Onuk EE, Fındık A, Turk N, Altun S, Korun J, Özer S, Avsever $\mathrm{ML}$, Çiftçi A. (2013) Molecular identification and determination of some virulence genes of Aeromonas spp. in fish and water from Turkish coastal regions. Revuc Med. Vet. 164, 200-2006.

21- Onuk EE, Durmaz Y, Çiftci A, Pekmezci GZ, Kılıçoğlu Y. (2015) Çeşitli Balık Türlerinden İzole Edilen Patojen Bakterilerin ve Antibiyotik Direnç Profilleri. Atatürk Üniversitesi Veteriner Bilimleri Dergisi. 10, 156-164.

22- Özkök S. (2005) Gökkuşağı alabalıklarında (Oncorhynchus mykiss) görülen önemli bakteriyel etkenlerin tespiti ve antibiyotiklere duyarlılıklarının saptanması. Etlik Veteriner Mikrobiyoloji Dergisi. 16, 1-2.

23- Öztürk RÇ, Altınok İ. (2014) Bacterial and Viral Fish Diseases in Turkey. Turkish Journal of Fisheries and Aquatic Sciences. 14, 275-297.

24- Rosso F, Cedano JA, Parra-Lara LG, Sanz AM, Toala A, Velez JF, Hormaza MP, Moncada PA, Correa A. (2019) Emerging carbapenem-resistant Aeromonas spp. infections in Cali, Colombia. Braz J Infect Dis. 23, 336-342.

25- Toranzo AE, Baya AM, Romalde JL, Hetrick FM. (1989) Association of Aeromonas sobria with mortalities of adult gizzard shad, Dorosoma cepedianim Lesueur. J. Fish Dis. 12, 439448.

26- Wahli T, Burr SE, Pugovkin D, Mueller O, Frey J. (2005) Aeromonas sobria, a causative agent of disease in farmed perch, Perca fluviatilis L. J. Fish Dis. 28, 141-150.

27- Wanja DW, Mbuthia PG, Waruiru RM, Mwadime JM, Bebora LC, Nyaga PN, Ngowi HA. (2019) Bacterial pathogens isolated from farmed fish and source pond water in Kirinyaga County, Kenya. International Journal of Fisheries and Aquatic Studies. 7, 295-301. 